\title{
HIGHLIGHTS
}

SCREENING

\section{Sensitivity versus specificity: neonatal screening for congenital hypothyroidism}

Newborn screening for congenital hypothyroidism $(\mathrm{CH})$ with a TSH cut-off point of $20 \mathrm{mU} / 1$ misses an appreciable number of permanent $\mathrm{CH}$ cases, according to the results of a Greek neonatal screening program published in the Journal of Clinical Endocrinology and Metabolism. However, lowering the TSH cut-off to $10 \mathrm{mU} / \mathrm{l}$ identified children with $\mathrm{CH}$ who would otherwise have escaped diagnosis.

Previous studies have highlighted that some cases of $\mathrm{CH}$ are missed during screening, a finding that was also observed in the Greek neonatal program, in which a $20 \mathrm{mU} / 1 \mathrm{TSH}$ cut-off value was used. This finding prompted Mengreli et al. to evaluate the consequences of lowering the TSH threshold to $10 \mathrm{mU} / \mathrm{l}$. The aim of the 3 -year prospective study was twofold: to uncover the number of cases previously missed by screening (false negatives) and to identify the underlying pathogenetic cause in these missed cases.

Mengreli et al. evaluated a population of 311,390 newborns who underwent
4 ...the lower cut-off applied resulted in improved sensitivity ... [but with] an increase in the number of false-positive results... 77

screening for $\mathrm{CH}$ at a single center in Greece. Of the infants diagnosed with $\mathrm{CH}$ $(n=200), 56(28 \%)$ presented with TSH values between $10 \mathrm{mU} / \mathrm{l}$ and $20 \mathrm{mU} / \mathrm{l}$. Follow-up of 47 infants with $\mathrm{CH}$ indicated that $40(85.1 \%)$ suffered from permanent $\mathrm{CH}$, a higher incidence than previously thought. Examination of the underlying causes of permanent $\mathrm{CH}$ revealed that eight infants (20\%) had an anatomical defect of the thyroid gland, whereas the remainder had a functional defect. Premature birth was associated with a high probability of missed diagnosis of permanent $\mathrm{CH}$.

Lowering the TSH cut-off point to $10 \mathrm{mU} / \mathrm{l}$ not only resulted in a 10 -fold increased recall rate, but also demonstrated that a sizable number of $\mathrm{CH}$ cases were missed by use of the higher TSH threshold. Nonetheless, the lower TSH cut-off point increased the number of falsepositive results by 10 -fold. The aim of an effective screening program is to deliver high sensitivity (no missed cases) while retaining specificity (a low number of falsepositive results). Mengreli highlights that "although the lower cut-off applied resulted in improved sensitivity, on the other hand, an increase in the number of false-positive results was observed, constituting a serious drawback." Mengreli concludes that further studies of the utility of their modified $\mathrm{CH}$ screening cut-off value for TSH are still required.

Rosanne Diaz

Original article Mengreli, C. et al. Screening for congenital hypothyroidism: the significance of threshold limit in falsenegative results. J. Clin. Endocrinol. Metab. doi:10.1210/ jc.2010-0057 